\title{
Use of Ecofriendly Glass Powder Concrete in Construction of Wind Farms
}

\author{
Eva M. García del Toro ${ }^{1, *}$, Daniel Alcala-Gonzalez ${ }^{1}\left(\right.$, María Isabel Más-López ${ }^{2}$, Sara García-Salgado ${ }^{1} \Subset$ \\ and Santiago Pindado ${ }^{3}$ (i)
}

check for

updates

Citation: García del Toro, E.M.; Alcala-Gonzalez, D.; Más-López, M.I.; García-Salgado, S.; Pindado, S. Use of Ecofriendly Glass Powder Concrete in Construction of Wind Farms. Appl. Sci. 2021, 11, 3050. https:// doi.org/10.3390/app11073050

\section{Academic Editors:}

Luis Hernández-Callejo, Maria del

Carmen Alonso García and Sara

Gallardo Saavedra

Received: 27 February 2021

Accepted: 24 March 2021

Published: 29 March 2021

Publisher's Note: MDPI stays neutral with regard to jurisdictional claims in published maps and institutional affiliations.

Copyright: (c) 2021 by the authors. Licensee MDPI, Basel, Switzerland. This article is an open access article distributed under the terms and conditions of the Creative Commons Attribution (CC BY) license (https:// creativecommons.org/licenses/by/ $4.0 /)$
1 Departamento de Ingeniería Civil, Hidráulica y Ordenación del Territorio ETSI Civil, Universidad Politécnica de Madrid Alfonso XII, 3, 28014 Madrid, Spain; d.alcalag@upm.es (D.A.-G.); sara.garcia@upm.es (S.G.-S.)

2 Departamento de Ingeniería Civil, Construcción, Infraestructura y Transporte ETSI Civil, Universidad Politécnica de Madrid Alfonso XII, 3, 28014 Madrid, Spain; mariaisabel.mas@upm.es

3 Instituto Universitario de Microgravedad "Ignacio Da Riva" (IDR/UPM), ETSI Aeronáutica y del Espacio, Universidad Politécnica de Madrid, Pza. del Cardenal Cisneros 3, 28040 Madrid, Spain; santiago.pindado@upm.es

* Correspondence: evamaria.garcia@upm.es

\begin{abstract}
Silicon is the main element in the composition of glass and it has been seen that it can be used as a partial replacement for cement in the manufacture of concrete. Different dosages of glass powder and cement were applied to manufacture the concrete mixes. Initially, the characteristics of fresh concrete were studied, such as consistency, air content, apparent density and workability. Secondly, compressive strength tests were performed on the different concrete mixtures produced. The consistency tests allowed us to classify these concretes within the group of fluids. The air content of these concretes increased with the rate of substitution of cement by glass powder, resulting in lighter concretes. Density tests showed that this parameter decreased as the rate of substitution of cement increased. A coefficient $k$ has been calculated for the substitution of glass powder by cement in the binder, using the Bolomey formula. Also, a mathematical model has been proposed to further analyze the experimental data. Major contributions of this work were to study the possible application of this concrete in different dispersions as a surface protection layer against the action of corrosion, in wind turbine foundations as well as the stabilization of the wind farm roads.
\end{abstract}

Keywords: sustainability; compressive strength; Bolomey formula; sustainable concrete; glass powder

\section{Introduction}

By designing the 2030 Agenda, the United Nations (UN) established 17 primary global objectives, the so-called SDGs (Sustainable Development Goals) [1], mainly focusing on eradicating poverty, protecting the planet by fighting climate change and defending the environment. It is a commitment and a challenge that must be addressed jointly, seriously and responsibly from all areas of society. Since ancient times, civil engineering has promoted the development of society through the construction of different types of infrastructures [2]. However, this development has caused severe environmental damage due to the large amount of natural resources demanded, as well as the pollution produced [3]. Current trends in the field of civil engineering are aimed at adapting to the SDGs by achieving resilient and sustainable infrastructures that contribute in some way to the circular economy, where the value of products and materials is kept as long as possible. Waste and the use of resources are minimized, as these resources are kept within the economy when a product has reached the end of its useful life in order to be repeatedly reused and continue creating value [4], and contributing to achieve innovative products that represent an economic benefit and a higher quality of life for people [5]. Therefore, it is important to carry out an evaluation of the efficiency and sustainability of the works to determine the degree of efficiency of the materials and construction methods [6]. 
Within the framework of the circular economy, the role of glass is worth highlighting [7]. Glass is a material that is easily recyclable due to its physical-chemical characteristics [7]. All types of glass waste are used in the recycling process, coming from the selective recovery of containers and packaging from the glass and ceramic industry [8].

Although in most industrialized countries the percentage of annually recycled glass is increasing, there is still a high percentage of glass that is disposed in landfill [9], which involves an important problem due to the accumulation of non-degradable waste, especially in highly populated areas [10].

Some of the problems to increase the recycling rate of glass waste come from the combination of different colors of glass waste, as well as difficulties in removing dirt, paper or other contaminants from glass products [11]. These wastes that cannot be recycled will be reused for certain uses.

Currently, there are many studies that show the good properties of glass waste, which cannot be recycled, as substitutes for certain materials in the preparation of mortars and concrete. They are considered indeed one of the most suitable substitutes for sand and cement, due to their physical characteristics and chemical composition [12-14]. This reuse of waste materials becomes a viable strategy to reduce the use of Portland cement and natural aggregates in the preparation of mortars and concretes, reducing environmental and energy impacts. Among these, the reduction of $\mathrm{CO}_{2}$ emissions is significant [14,15], as well as of areas destined for controlled landfills $[13,16]$. In this context, the so-called eco-efficient concretes arise, which comply with the characteristics outlined, but, in some cases, they have some worse properties, such as compressive strength or durability, when compared to those made with natural materials [16].

The use of finely grinded glass powder in the manufacture of mortars and concretes has been widely studied, especially the optimum particle size. Most of the studies have focused on assessing how the properties of concrete vary depending on the substitution percentage of cement by glass powder, as well as its particle size, which has been shown to play a vital role in the alkali-silica reaction (ASR) [17-19]. At this regard, and according to Idir et al. [19], with a particle size between 0.9 and $1 \mathrm{~mm}$ and a substitution percentage of $20 \%$ with glass powder, the classic contractions due to ASR do not occur. Corinaldesi et al. [20] stated that up to a substitution percentage of the aggregates by glass powder of $70 \%$ can be reached, provided that a particle size between 36 and $50 \mu \mathrm{m}$ is used. This showed that by reducing the particle size of glass powder, the pozzolanic properties of the binders manufactured increase. In addition, a greater long-term strength resistance of the pastes manufactured with this type of cement was obtained, due to the higher presence of C-S-H gels $[19,20]$. Also, these gels have a self-repairing property when they are used in the stabilization of rolling track soils by prolonging their setting over time [21].

Liu [22] reported that self-compacting concrete produced with $10 \%$ glass powder to replace cement had good properties when fresh. They indicated that workability decreased as the glass powder content of the concrete increased due to the geometry of the glass dust. In the same line, Parghi et al. [13] indicated that the sharper edge and the more angular shape of the glass powder (GP) particles reduced the fluidity of the cement mortars and concretes.

Nassar and Soroushian [23] reported pozzolanic activity when glass powder with a particle size of $13 \mu \mathrm{m}$ was used as a fractional replacement for cement in concrete. Schwarz et al. [24] studied the properties of ground glass powder and reported that up to a certain percentage substituting ground glass for cement was a viable solution for fabrication in concrete.

Studies carried out by Sahyan et al. [25] have shown that at constant water-to-binder mass ratio, the addition of $20 \%$ of glass powder significantly reduced the chloride ion permeability of concrete, which was confirmed by Schawrz et al. [21]. This property confers protective properties against corrosion to concretes made with glass powder and cement. 
Shaoa et al. [23] observed an increase in compressive strength of $120 \%$ at the cure age from 3 to 90 days, when concrete was produced with ground glass powder with particle size up to $38 \mu \mathrm{m}$.

According to Pengwei et al. [24], in the traditional concrete used in civil construction that is generally subjected to large changes in temperature, its durability is clearly affected, and in extreme cases can leave the concrete out of service. To avoid these consequences in traditional concretes, air-entraining additives are incorporated into the mix. In the case of concrete made with glass powder as a binder, the higher the percentage of substitution of glass powder for cement, the higher the air content, so it is not necessary to include additives.

In 1935, Bolomey gave a formula to predict the compressive strength of cement mortar, which expresses a linear relationship between the water-cement ratio and compressive strength. This expression indicates that compressive strength of cement-based materials is mainly dependent on the water-cement ratio among all the other factors. Therefore, it is seen as a mathematical form of water-cement ratio law. In this regard, based on Fernández Cánovas studies [25], a calculation of theoretical compressive strengths at 28 and 90 days was reported using Bolomey's dosage, introducing a coefficient $k$ that represented the replacement of cement CEM I52.5 $\mathrm{R}$ by glass powder.

Considering all the above-mentioned points, our initial research hypothesis was that the glass powder used in this work, with its characteristics and particle size, will allow us to produce an ecofriendly concrete, whose mechanical properties will not be adequate to use it as a structural concrete, but it may be useful as a surface protection layer to avoid or reduce corrosion phenomenon. Therefore, the aim of this work consisted of studying the compressive strength of cements produced with different substitution percentages of a certain glass powder. A mathematical model has been proposed to fit the experimental compressive strength results. Also, Bolomey's formula was applied for simulation of the relationship between the water-cement ratio and 28- and 90-day compressive strength.

In summary, major contributions of this work were to study the possible application of concrete made with cement and glass powder in different dispersions as a surface protection layer against the action of corrosion, in wind turbine foundations as well as the stabilization of the wind farm roads, since it is a sustainable and environmentally friendly material. On the other hand, the mathematical model developed has resulted in an appropriate simulation tool, since errors between real and simulated final stable values of compressive strength were lower than 3.3\%. Finally, it has been proved that glass powder exerted an important activity in increasing the long-term compressive strength of concretes, according to results obtained by the application of Bolomey's formula. Also, the use of glass powder as a binder in the concrete would be beneficial from the point of view of the circular economy and environmental footprint because a final waste, which cannot be further recycled and whose destiny would be a landfill, may have another useful application.

\section{Materials and Methods}

\subsection{Materials}

CEM I 42.5-R Portland cement (Cementos Portland Valderrivas, Morata de Tajuña, Madrid, Spain) was used. This cement had a density of $3.12 \mathrm{~g} / \mathrm{cm}^{3}$, a specific surface of $4.440 \mathrm{~cm}^{2} / \mathrm{g}$ and a green-gray color. Its chemical composition was as follows- $\mathrm{CaO}(65 \%)$, $\mathrm{SiO}_{2}(19 \%), \mathrm{Al}_{2} \mathrm{O}_{3}(5.5 \%), \mathrm{Fe}_{2} \mathrm{O}_{3}(2.65 \%), \mathrm{SO}_{3}(2 \%), \mathrm{MgO}(2 \%), \mathrm{Na}_{2} \mathrm{O}(0.15 \%), \mathrm{K}_{2} \mathrm{O}(0.7 \%)$.

The aggregate in mortar was essentially siliceous and non-reactive. It was sand with a granulometry $<4 \mathrm{~mm}$, gravel $4-12 \mathrm{~mm}$ and gravel $12-20 \mathrm{~mm}$.

The glass powder used came from the grinding of waste from the ceramic industry, as well as from containers and packaging from the selective rubbish collection, which cannot be reused due to their characteristic (high percentage of paper, cork or plastic attached). They have been ground in a bar mill equipped with 15 bars of 3 different diameters and with different grinding times. 
d50 glass powder of $16 \mu \mathrm{m}$ was used (dimension of sample particles for which $50 \%$ of them have a diameter lower than a certain value) [8], which provides interesting mechanical results at a cost energy clearly lower than that necessary to obtain smaller granulometries of glass powder. This makes the use of this material more sustainable in the field of Civil Engineering [26].

Chemical composition of glass powder was given by the manufacturing company. It is composed by $71.00 \% \mathrm{SiO}_{2}, 11.80 \% \mathrm{Na}_{2} \mathrm{O}, 11.28 \% \mathrm{CaO}, 2.20 \% \mathrm{Al}_{2} \mathrm{O}_{3}, 1.60 \% \mathrm{Fe}_{2} \mathrm{O}_{3}, 1.40 \%$ $\mathrm{MgO}, 0.60 \% \mathrm{~K}_{2} \mathrm{O}, 0.10 \% \mathrm{MnO}, 0.07 \% \mathrm{TiO}_{2}$ and $0.05 \% \mathrm{P}_{2} \mathrm{O}_{5}$, with $0.90 \%$ volatile $\mathrm{LF}$ (lost of the Fire).

Physical and mechanical characteristics of the waste used were obtained by means of different analysis techniques-laser granulometry, X-ray Diffraction and Scanning Electron Microscopy. It should be noted that all the aforementioned ground glass powder comes from the same batch of waste. Only their granulometries vary.

\subsection{Characterization of Fresh Concrete}

Consistency tests were carried out using the UNE-EN 12350-5 standard [27], by means of the settlement test, which is sensitive when the mean settlement is between 10 and $200 \mathrm{~mm}$. The air content of prepared concrete was determined by the UNE-EN 12350-7 standard [28] by pressure methods. The procedure followed for the calculation of density and porosity was based on the corresponding standard [29].

\subsection{Sample Preparation}

In order to evaluate the different characteristics of concrete, 6 series of test pieces were manufactured in accordance with the UNE-EN 12390-2 standard [30]. The only difference between these specimens was the amount of glass powder used to replace the CEM I 52.5 $\mathrm{R}$ cement, as described in Table 1.

Table 1. Summary of experimental conditions for the samples prepared.

\begin{tabular}{|c|c|c|c|c|c|c|}
\hline \multirow{2}{*}{ Concrete Composition } & \multicolumn{6}{|c|}{ Sample ID } \\
\hline & Control & G15 & G30 & G45 & G60 & G80 \\
\hline Cement substitution rate for glass powder $(\%)$ & 0 & 15 & 30 & 45 & 60 & 80 \\
\hline Cement CEM I 52,5 R $\left(\mathrm{kg} / \mathrm{m}^{3}\right)$ & 330 & 280.5 & 231 & 181.5 & 132 & 66 \\
\hline Glass Powder $\left(\mathrm{kg} / \mathrm{m}^{3}\right)$ & 0 & 49.5 & 99 & 148.5 & 198 & 264 \\
\hline Equivalent binder $\left(\mathrm{kg} / \mathrm{m}^{3}\right)$ & \multicolumn{6}{|c|}{330} \\
\hline Plasticizer (\% binder) & \multicolumn{6}{|c|}{0.35} \\
\hline Total water $(\mathrm{L})$ & \multicolumn{6}{|c|}{184} \\
\hline Arid $<4 \mathrm{~mm}$ & \multicolumn{6}{|c|}{740} \\
\hline Gravel 4-12 mm & \multicolumn{6}{|c|}{310} \\
\hline Gravel $12-20 \mathrm{~mm}$ & \multicolumn{6}{|c|}{850} \\
\hline
\end{tabular}

All the mixtures were completely homogenized and poured into $10 \times 30 \mathrm{~cm}$ cylindrical molds. They were compacted and after $24 \mathrm{~h}$ they were removed from the mold and kept in a humid curing chamber at $20^{\circ} \mathrm{C}$, for $2,7,28,90$ and 180 days. After this time, the test tubes were broken in accordance with the instructions of the UNE 83-304-84 standard [31], and the properties of compressive strength of manufactured concretes were determined.

\section{Results and Discussion}

\subsection{Characterization of Glass Powder}

Three grinding processes were carried out on the waste glass, each one for a different time, in order to obtain three samples of glass powders with different particle sizes.

Three dimensions have characterized the glass powders-d10, d50 and d90. They represent, respectively, the diameter of the sample particles for which $10 \%, 50 \%$ and $90 \%$ of the particles have a diameter smaller than that dimension, as can be seen in Table 2. In 
this work, the value of d50 was used for the characterization of the different batches of ground glass.

Table 2. Granulometric characteristics of glass powders produced as a function of grinding time.

\begin{tabular}{ccccc}
\hline Glass Powder Used & Griding Duration & $\mathbf{d}_{\mathbf{1 0}}$ & $\mathbf{d}_{\mathbf{5 0}}$ & $\mathbf{d}_{\mathbf{9 0}}$ \\
\hline T1 & $2 \mathrm{~h} 30$ & $2.92 \pm 0.01 \mu \mathrm{m}$ & $33 \pm 1 \mu \mathrm{m}$ & $110 \pm 3 \mu \mathrm{m}$ \\
$\mathrm{T} 2$ & $4 \mathrm{~h} 15$ & $1.96 \pm 0.01 \mu \mathrm{m}$ & $16 \pm 1 \mu \mathrm{m}$ & $59 \pm 2 \mu \mathrm{m}$ \\
$\mathrm{T} 3$ & $5 \mathrm{~h}$ & $1.65 \pm 0.01 \mu \mathrm{m}$ & $11 \pm 1 \mu \mathrm{m}$ & $43 \pm 2 \mu \mathrm{m}$ \\
\hline
\end{tabular}

The cumulative granulometric curves of the three samples (Figures 1 and 2) revealed considerable differences in the distribution of particle size.

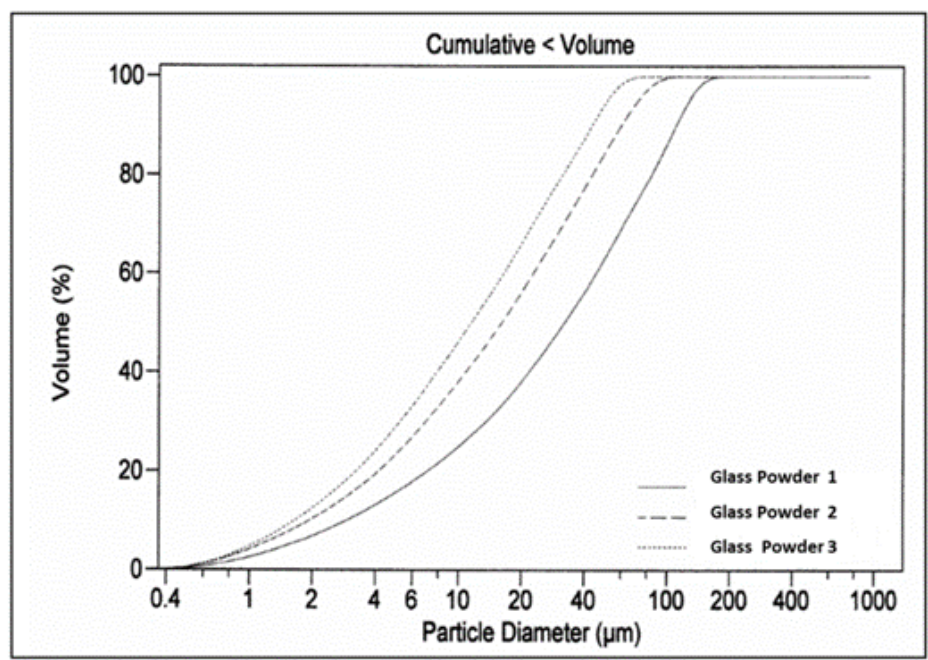

Figure 1. Distribution of the accumulated granulometry of the 3 batches of glass powder [32].

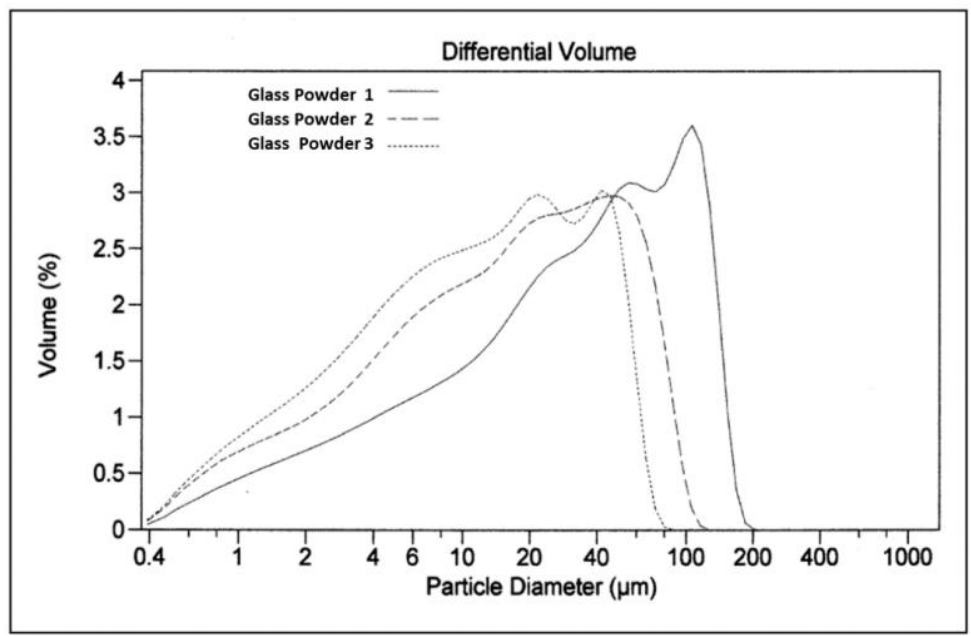

Figure 2. Differential particle size distribution of the 3 batches of glass powder [32].

The glass powder subjected to X-ray diffraction tests resulted in a broad diffraction band between 15 and 45 degrees, which corresponded to its amorphous and disordered structure. The X-ray diffractogram of the glass powder of $d 50=16 \mu \mathrm{m}$ is shown in Figure 3 . 


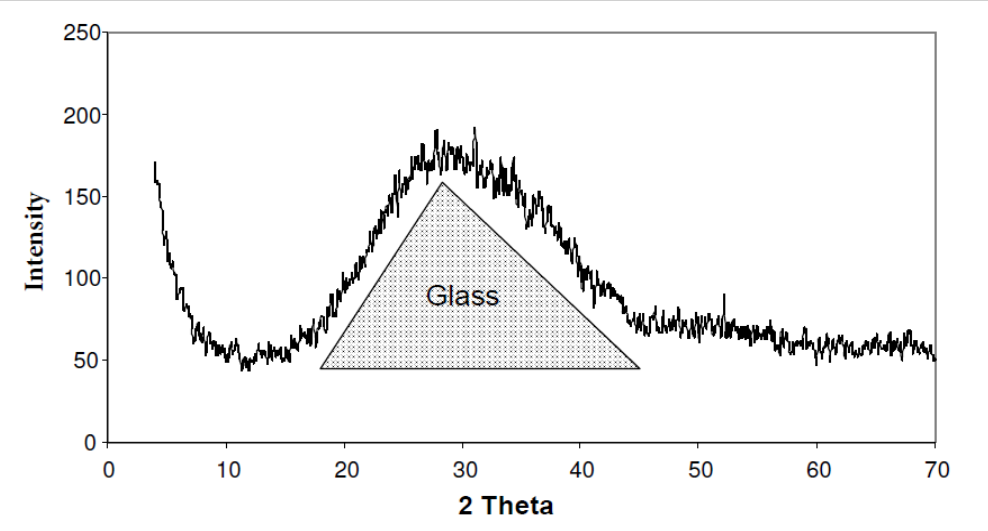

Figure 3. X-ray diffractogram of the glass powder of $\mathrm{d} 50=16 \mu \mathrm{m}$. The dotted area shows the bulging of the baseline indicating the presence of amorphous phases [32].

By means of the observation through the Scanning Electron Microscope (SEM), glass grains with particle size between 1 and $20 \mu \mathrm{m}$ can be observed. These grains showed acicular shape and cone-shaped fractures. It should be noted the absence of fine elements attached to these glass particles and their low porosity. A frontal and side views of a glass powder particle, obtained by SEM, are shown in Figure 4.
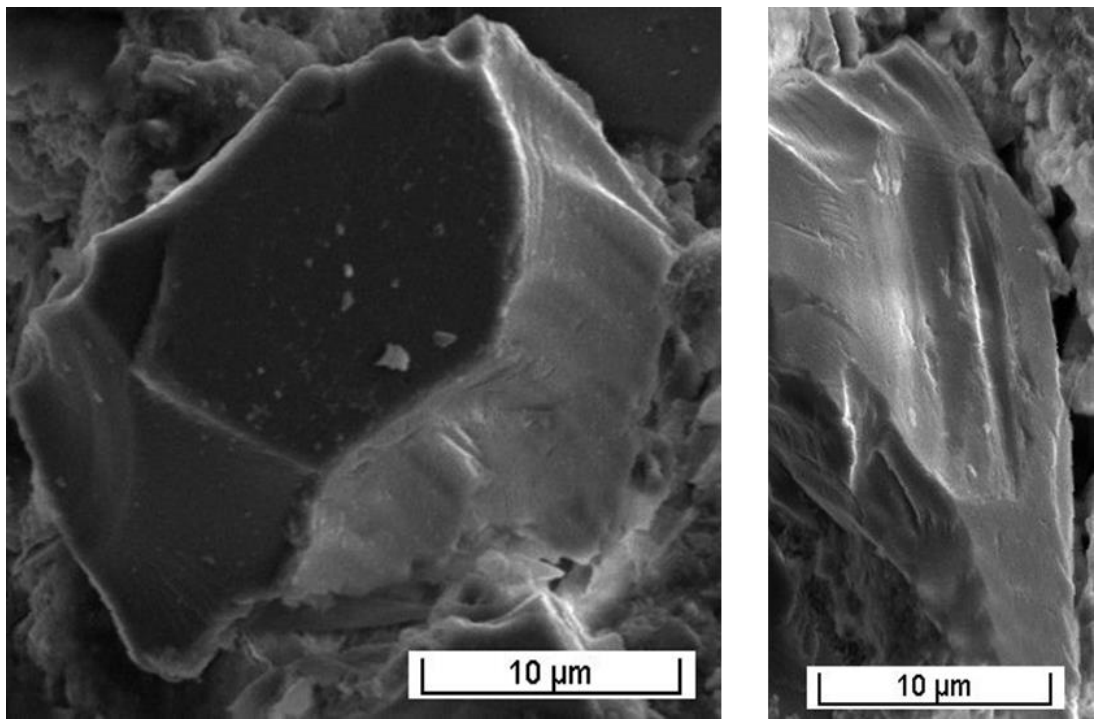

Figure 4. View of a glass powder particle (scanning electron microscopy (SEM) cliche in secondary electrons). Frontal view (left) and side view (right) [32].

\subsection{Results of the Characterization of Concrete}

Results obtained for consistency, air content, apparent density and workability tests are shown in Table 3. 
Table 3. Results obtained in the characterization of fresh concrete and concrete substituted by glass powder.

\begin{tabular}{ccccccc}
\hline & Control & G15 & G30 & G45 & G60 & G80 \\
\hline Consistency $(\mathrm{mm})$ & 11 & 16 & 16 & 16 & 14 & 13 \\
$\begin{array}{c}\text { Air content }(\%) \\
\text { Apparent density }\end{array}$ & 2.8 & 3.9 & 5.0 & 5.0 & 6.8 & 7.5 \\
$\begin{array}{c}\left.\text { Wg/m }{ }^{3}\right) \\
\text { Workability }\end{array}$ & 2390.1 & 2351.0 & 2338.5 & 2330.5 & 2292.0 & 2282.0 \\
$($ easy/difficult) & easy & easy & easy & medium & medium & difficult \\
\hline
\end{tabular}

According to the results obtained for the consistency tests, carried out by means of a settlement test, concretes studied can be classified within the group of fluid concretes, regardless of their dosage. It can be observed that the penetration values decreased as the amount of glass powder added to the mixture increased, which is in agreement with the results obtained by Liu [22]. Regarding the air content, it varied from $3.9 \%$ to $7.5 \%$, so air content increased with the substitution rate of the CEM I $52.5 \mathrm{R}$ cement by glass powder. Therefore, it can be said that replacing cement with glass powder led to a higher air content. This phenomenon is caused by the retention of air bubbles by the surface energy of the glass, which is greater the finer the glass grains are. For this reason, the volumetric mass of the different concretes varied, decreasing when the substitution of cement for glass powder increased. In addition to air, a second cause intervened in the decrease in the volumetric mass of the concretes, which was the volumetric mass difference between glass and cement. This is because the substitutions of CEM I $52.5 \mathrm{R}$ cement for glass powder were mass substitutions that were made without the volumetric corrections due to the presence of aggregates.

Workability decreased when the amount of glass powder in the binder increased, also in accordance with the tests carried out by Liu et al. [22].

The densities of the different concretes manufactured for this study were between 2351 and $2282 \mathrm{~kg} / \mathrm{m}^{3}$, so density decreased as the rate of substitution of cement for glass powder increased. This is not in agreement with some authors, for example, Parghi et al. [13], who reported that the density was higher the higher the percentage of glass contained in the mixture was. This may be due to the volumetric mass of the cement used, which was $3.12 \mathrm{~g} / \mathrm{cm}^{3}$, while that of the glass powder was $2.54 \mathrm{~g} / \mathrm{cm}^{3}$.

Regarding workability, the results obtained for the manufactured concretes did not show significant changes. This result is in agreement with those obtained by Pereira-deOliveira et al. [33] and Taha et al. [34].

\subsection{Mechanical Properties of Concrete}

Table 4 presents the compressive strengths of manufactured concretes, with and without cement replacement with glass powder (see Table 1 for dosages), for all test ages $(2,7,28,90$ and 180 days $)$.

Table 4. Compressive strength of concrete manufactured with cement replaced by glass powder.

\begin{tabular}{ccccccc}
\hline \multirow{2}{*}{$\boldsymbol{t}$ (Days) } & \multicolumn{7}{c}{ Compressive Strength (MPa) } \\
\cline { 2 - 7 } & Control & G15 & G30 & G45 & G60 & G80 \\
\hline 2 & 22.4 & 17.3 & 12.4 & 8.6 & 2.7 & 0.5 \\
7 & 29.9 & 25.9 & 20.4 & 15.9 & 5.0 & 1.5 \\
28 & 34.5 & 32.0 & 23.9 & 21.2 & 10.0 & 3.7 \\
90 & 39.6 & 32.6 & 29.8 & 25.2 & 14.2 & 8.6 \\
180 & 40.4 & 33.8 & 30.7 & 26.9 & 15.8 & 10.3 \\
\hline
\end{tabular}

As can be observed, for concrete prepared with cement replaced by glass powder, the compressive strength of the concrete decreased when the quantity of glass powder in the 
binder increased. This can be attributed to the fact that glass powder has a low pozzolanic activity at the early ages. These results are in agreement with the results obtained by Tan et al. [35] and Mizahosseini et al. [36].

\subsubsection{Mathematical Analysis of the Experimental Results}

A mathematical model has been proposed to further analyze the experimental data. The results obtained fit the following equation:

$$
C s=C s_{0}\left(1-\exp \left(-\left(\frac{t}{\tau}\right)^{n}\right)\right)
$$

close to the one that defines a first order system in classical mechanics (a similar model has been used by Fiol et al. [37] In the above equation, $C s$ is the compressive strength, $C s_{0}$ is the final stable value of the compressive strength, $t$ stands for the number of days after setting, $n$ is a shape constant, and $\tau$ is a characteristic time that represents the time when the compressive strength reaches a $63 \%$ of its final value. The results of the fittings, together with the Root Mean Squared Error, RMSE:

$$
\mathrm{RMSE}=\sqrt{\frac{1}{N} \sum_{i=1}^{N}\left(\left.C s\right|_{\text {measured }}-\left.C s\right|_{\text {calculated }}\right)^{2}}
$$

are presented in Table 5. The results of the modeling have been plotted in Figure 5 with dashed lines.

Table 5. Coefficients of Equation (1), $C s_{0}, \tau$, and $n$, fitted to the measured values of the compressive strength, for each one of the studied cases (see Table 4), together with the Root Mean Squared Error (RMSE) of each fitting.

\begin{tabular}{ccccccc}
\hline & Control & G15 & G30 & G45 & G60 & G80 \\
\hline $\mathrm{Cs}_{0}(\mathrm{MPa})$ & 41.89 & 33.237 & 31.978 & 26.964 & 16.618 & 11.011 \\
$\tau(\mathrm{d})$ & 1.5979 & 2.0105 & 2.4732 & 3.3509 & 9.3934 & 59.627 \\
$n$ & 4.1999 & 3.4191 & 9.4455 & 10.810 & 32.400 & 62.276 \\
$\mathrm{RMSE}$ & 0.608 & 0.364 & 1.025 & 0.634 & 0.107 & 0.226 \\
$(\mathrm{MPa})$ & & & & & & \\
\hline
\end{tabular}

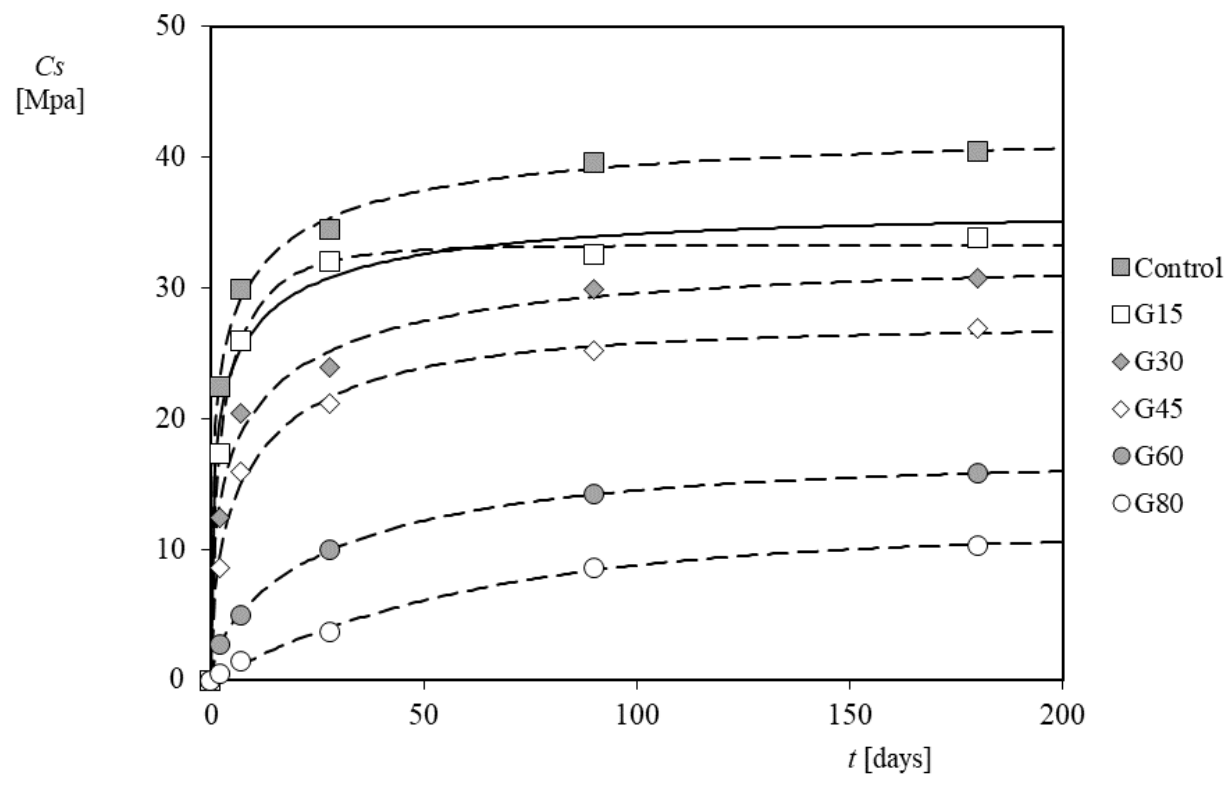

Figure 5. Evolution over time after setting of concrete compression strengths, Cs, for different cases studied (see Tables 1 and 4). 
The model has proven to simulate quite well the results, as the errors were between $0.65 \%$ and $3.21 \%$ in relation to the calculated values of $C s_{0}$. Results of the model fitting to the $G_{15}$ sample were slightly different, as the shape of its curve seemed to detach from the general pattern shown by the curves fitted to the data from the other cases. In Figure 6, the coefficients of Equation (1) extracted from the different samples data are plotted in relation to the amount of glass powder used to replace the cement, Gp. The following equations were fitted to the results (see the dashed lines in graphs from Figure 5):

$$
\begin{gathered}
C s_{0}=41.54-38.06 C_{s}\left(R^{2}=0.967\right) \\
\tau=2.8477+46.875 C_{s}^{2}+73.28 C_{s}^{4}\left(R^{2}=0.986\right) \\
n=0.3266+1.0277 C_{s}^{2.172}\left(R^{2}=0.857\right)
\end{gathered}
$$
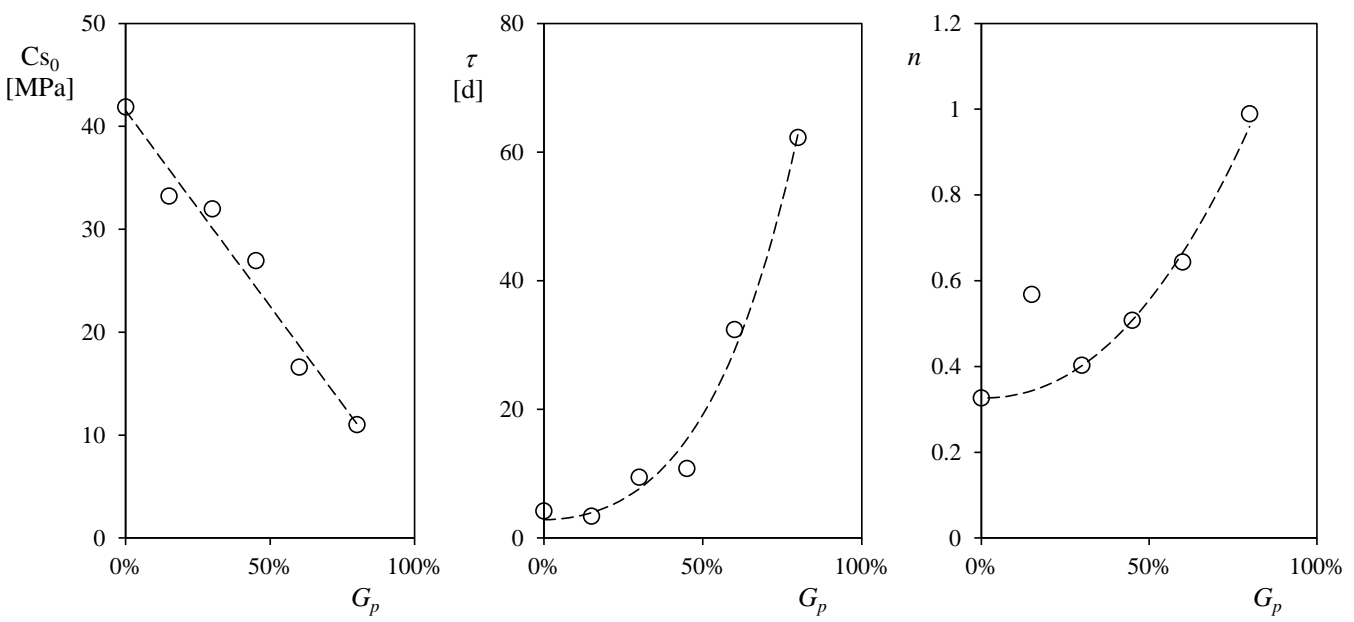

Figure 6. Coefficients of Equation (1), $C s_{0}, \tau$, and $n$, plotted in relation to the amount of glass powder used to replace the cement, Gp. The corresponding lines of tendency (Equations (3)-(5)) have been plotted as dashed lines.

From Figure 5, it can be seen that the coefficient $n$ from the $\mathrm{G}_{15}$ sample did not fit Equation (5), making the fitting of Equation (1) to this sample data (see Figure 5) slightly different from the general pattern. This might indicate that the normal errors present in the process of manufacturing the samples has larger effects for lower quantities of glass powder replacing the cement (that is, for lower values of $G p$ ). Finally, with the coefficients extracted from the above equations for $G p=15$, the modeling of the sample G15 has been calculated and plotted in Figure 5 with a solid line. The fitting was worse to the experimental data than the one obtained from the direct fitting of Equation (1), with the error being larger $($ RMSE $=4.32 \%)$.

\subsubsection{Simulation by Bolomey's Formula}

As previously mentioned, Bolomey's formula allows us to predict the compressive strength by means of a linear relationship between the water-cement ratio and compressive strength. According to Bolomey's law, by introducing a coefficient for a certain admixture, the compressive strength values of a concrete in which this admixture has been included as part of the binder can be estimated. From this equation, the effect of such addition on the compressive strengths of concrete can be measured:

$$
C s=\operatorname{Csm} \times G\left(\frac{C+k+A}{V}-0.5\right)
$$


where:

Cs: Compressive strength of concrete (MPa);

Csm: Compressive strength of a mortar of the same age (MPa);

G: Granular coefficient;

$C$ : Amount of cement per $\mathrm{m}^{3}$ of concrete $\left(\mathrm{kg} / \mathrm{m}^{3}\right)$;

$k$ : additive coefficient; and

$V$ : volume of water per $\mathrm{m}^{3}$ of concrete $\left(1 / \mathrm{m}^{3}\right)$

Using the above Equation (6), the theoretical values, at 28 and 90 days, of the compressive strengths of concrete in which a part of the CEM I 52.5 R cement has been replaced by an inert additive $(k=0)$, were calculated. Table 6 shows the so-called 'Bolomey compressive strengths-Bolomey $C s^{\prime}$ obtained. In this table, Bolomey's 'apparent' compressive strengths and 'apparent' coefficients of the additive correspond to values calculated without correcting for the secondary effect of air entrainment caused by glass dust. Bolomey's 'real' compressive strengths and 'real' coefficients of the additive indicate values calculated after correcting for this effect.

Table 6. Results of Bolomey's 'apparent' and 'real' compressive strengths.

\begin{tabular}{|c|c|c|c|c|c|c|}
\hline Bolomey Compressive Strengths (MPa) & Control & G15 & G30 & G45 & G60 & G80 \\
\hline Cs 28 (Bolomey) apparent $(k=0)$ & 34.5 & 23.7 & 14.9 & 8.1 & 0 & / \\
\hline Cs 28 (Bolomey) real $(k=0)$ & 34.5 & 25.7 & 18.1 & 10.6 & 3.0 & / \\
\hline Coefficient considering the apparent $\mathrm{k}$ addition at 28 days & / & 1.01 & 0.57 & 0.59 & 0.36 & 0.35 \\
\hline Coefficient considering the real $\mathrm{k}$ addition at 28 days & / & 0.67 & 0.30 & 0.42 & 0.20 & 0.24 \\
\hline \multicolumn{7}{|l|}{ Compressive strengths and coefficients considering the addition } \\
\hline Cs 90 (Bolomey) apparent $(k=0)$ & 39.6 & 27.2 & 17.1 & 9.3 & 0 & / \\
\hline Cs 90 (Bolomey) real $(k=0)$ & 39.6 & 29.5 & 20.8 & 12.2 & 3.4 & / \\
\hline Coefficient considering the apparent $\mathrm{k}$ addition at 90 days & / & 0.5 & 0.71 & 0.63 & 0.20 & 0.25 \\
\hline Coefficient considering the real $\mathrm{k}$ addition at 90 days & / & 0.20 & 0.42 & 0.45 & 0.15 & 0.34 \\
\hline
\end{tabular}

Figure 7 shows the evolution over time of the compressive strengths of the concrete specimens, at a test age of 28 days, compared to Bolomey's 'apparent' and 'real' compressive strengths. As can be seen, the use of glass powder in the binder increased the compressive strengths of concrete in the long term, increasing their values slightly between 28 and 90 days. It seems that the particle size of glass powder was one important factor responsible for the increased reactivity in the long term [38].

Figure 8 shows the evolution over time of the compressive strengths of the concrete specimens, at a test age of 90 days, compared to Bolomey's 'apparent' and 'real' compressive strengths.

The differences between the 'apparent' and 'real' Bolomey compressive strengths (Figures 7 and 8) were due to the effect of air entrainment caused by glass powder. It is observed that the compressive strengths of concretes containing glass powder were clearly greater than those so-called Bolomey ones, whatever the amount of glass powder that the binder contained. It can be concluded, therefore, that glass dust exerted an important activity in increasing the long-term compressive strength of concretes. This activity can be represented by a coefficient $k$, at 28 and 90 days, shown in Figures 9 and 10, which present the evolution of the value of ' $k$ apparent' and ' $k$ real' depending on the amount of glass powder contained in the binder, respectively. 


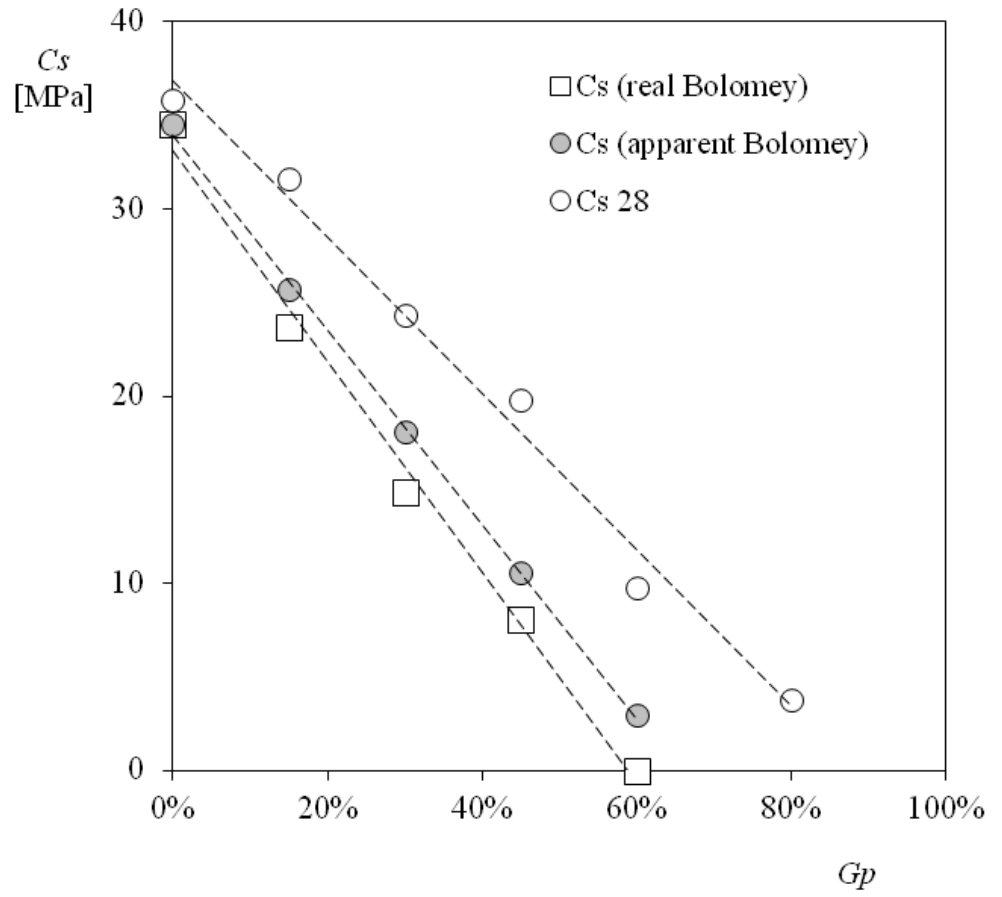

Figure 7. Compressive strength, Cs, 28 days after setting, with regard to the amount of glass powder used to replace the cement $(G p)$. The results are compared to the Bolomey (real and apparent) corresponding ones. The determination coefficients of the linear fittings are $R^{2}=0.988\left(C_{S} 28\right) ; R^{2}=$ $0.999\left(C_{S}\right.$ apparent Bolomey); $R^{2}=0.993\left(C_{S}\right.$ real Bolomey).

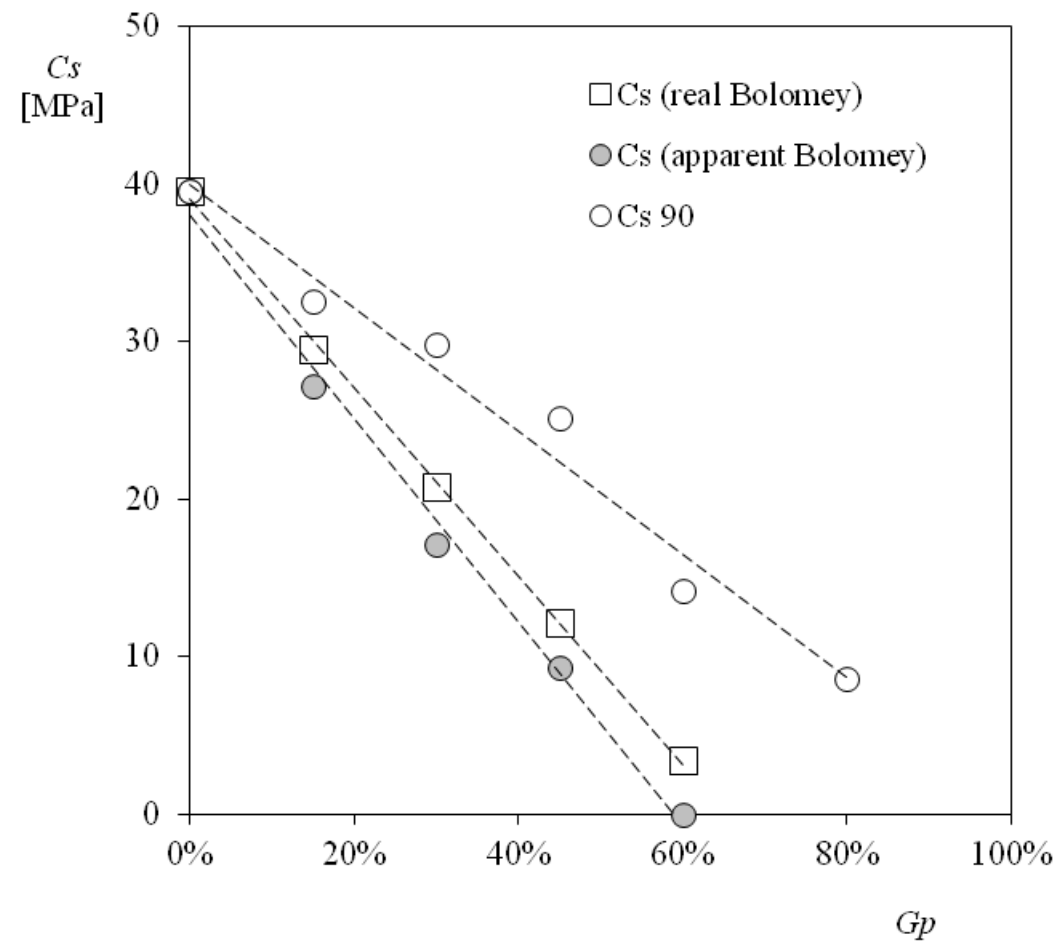

Figure 8. Compressive strength, Cs, 90 days after setting, with regard to the amount of glass powder used to replace the cement $(G p)$. The results are compared to the Bolomey (real and apparent) corresponding ones. The determination coefficients of the linear fittings are $R^{2}=0.973\left(C_{S} 90\right) ; R^{2}=$ $0.993\left(C_{S}\right.$ apparent Bolomey); $R^{2}=0.999\left(C_{S}\right.$ real Bolomey $)$. 


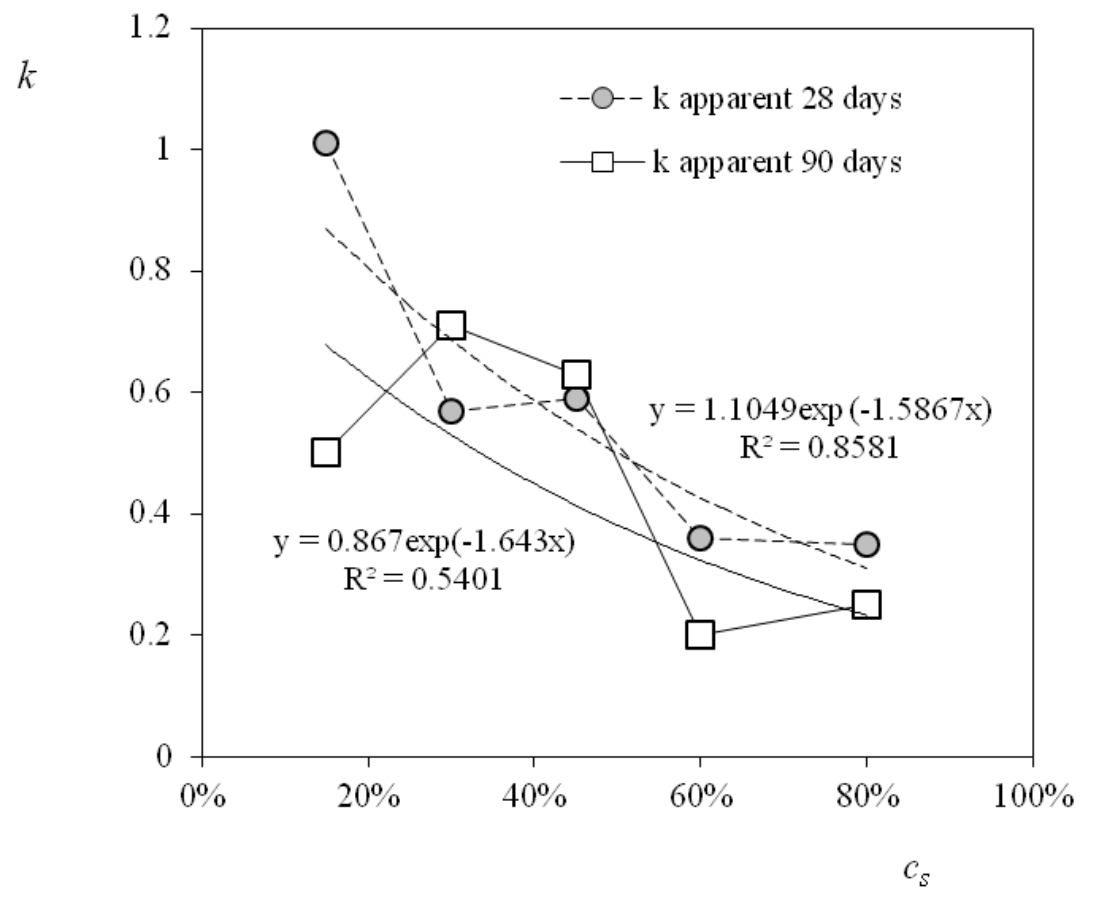

Figure 9. Evolution of the value of ' $k$ apparent' depending on the amount of glass powder contained in the binder $(G p)$.

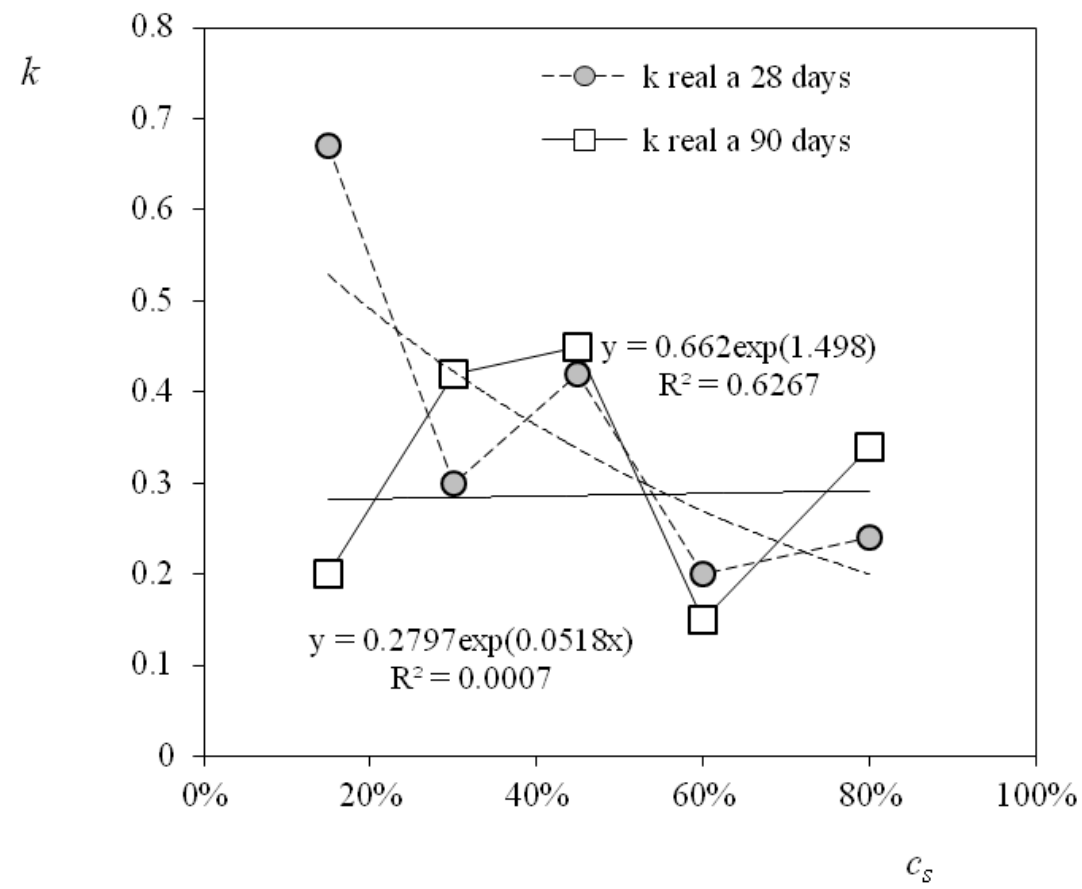

Figure 10. Evolution of the value of ' $k$ real' depending on the amount of glass powder contained in the binder $(G p)$.

Taking into account the precision of these measurements, two average values of ' $k$ ' can be obtained, one for substitutions lower than 50\% of CEM I $52.5 \mathrm{R}$ cement for glass powder, and the other for substitutions higher than $50 \%$.

In this way, it can be considered that ' $k$ apparent' was equal to 0.6 , for replacements of cement for glass powder below $50 \%$, and equal to 0.3 for those higher. Similarly, for ' $k$ real' a value of 0.4 can be considered for substitutions of cement for glass powder below $50 \%$, and 0.3 for those higher. These results are interpreted so that if $k$ was 0.6 , for example, to 
obtain the same compressive strength in a concrete produced with $60 \mathrm{~kg}$ of CEM I $52.5 \mathrm{R}$ cement, it would be necessary to use $100 \mathrm{~kg}$ of glass powder.

By obtaining the so-called Bolomey coefficients, the percentage of cement that can be replaced for glass powder in concrete to obtain a certain compressive strength can be calculated. According to Figures 9 and 10, for up to 50\% replacement of CEM I 52.5 $\mathrm{R}$ cement by glass powder, the compressive strength values of concretes are sufficiently important to classify these concretes in the group of building concretes. It was observed that the decrease in compressive strength occurred linearly as a function of the percentage of glass powder in the binder. In this way, from the experimental results, taking into account the percentage of glass powder contained in the binder and the compressive strength obtained in the control specimen, Equation (7) has been deduced. Such an equation makes it possible to predict the compressive strength of the concrete, at a certain setting time, according to the amount of glass powder used to replace the CEM I 52.5 cement:

$$
C s=-31 V+C s_{c e m}
$$

where:

$V$ is the percentage of glass powder contained in the binder; and $\mathrm{Cs}_{\text {cem }}$ is the compressive strength of the concrete whose binder is only CEM I $52.5 \mathrm{R}$.

Figure 11 shows the variation of compression strengths, for test ages of 2, 7, 28 and 90 days, of concrete manufactured with different replacement percentages of cement by glass powder. At above 50\% replacement of CEM I $52.5 \mathrm{R}$ cement by glass powder, the previous law is not applicable. The experimental values of compressive strength are lower than those obtained by this expression. From the values obtained for compressive strength, concretes studied can be classified in the group of concretes for paving roads and highways. Also, a possible use of concrete with a substitution percentage of glass powder for cement lower than $50 \%$ may be in the construction of wind farms, as a surface layer in foundations, since it may reduce the effects caused by corrosion because it significantly reduces the chloride ion permeability of concrete due to exposure to meteorological phenomena $[25,26]$.

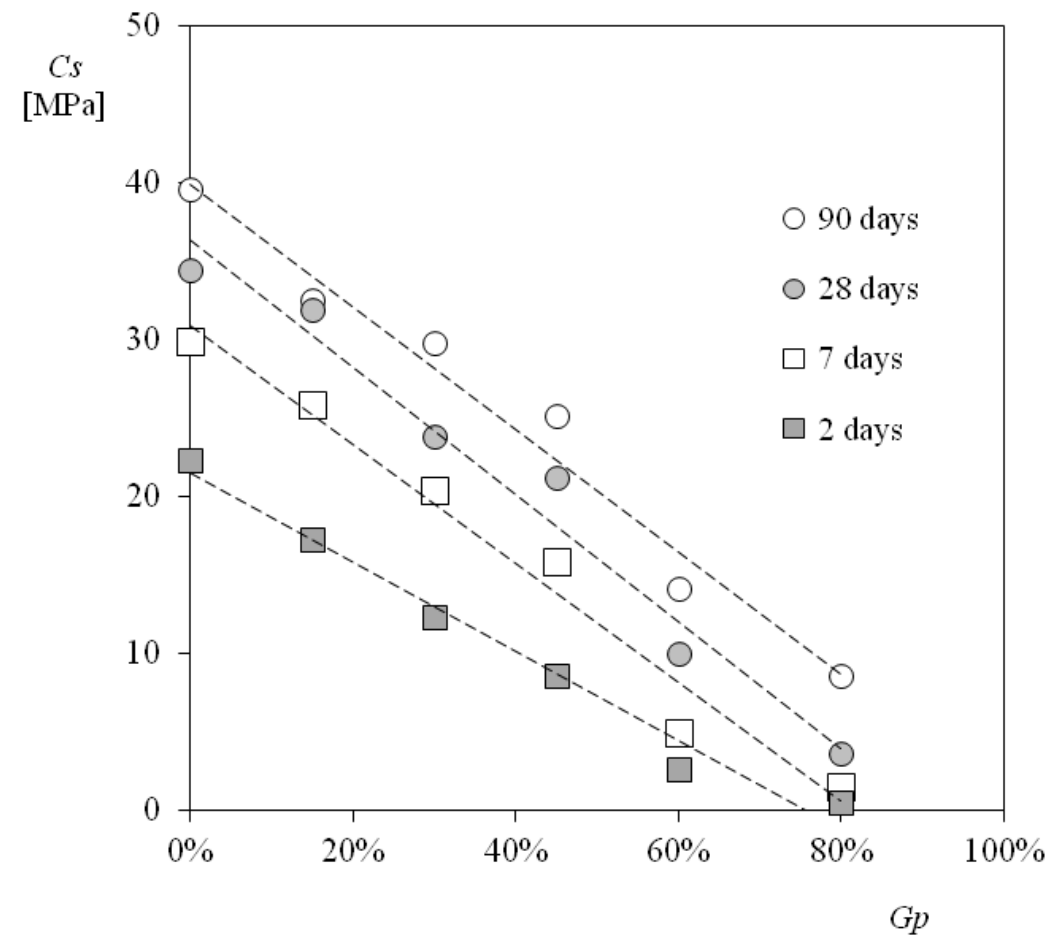

Figure 11. Variation of compression strengths, for test ages of 2, 7, 28 and 90 days, of concrete manufactured with different replacement percentages of cement by glass powder $(G p)$. 
On the other hand, concretes manufactured with a replacement percentage higher than $50 \%$ of glass powder could be involved in the construction of park roads, especially in those located in areas with a high ecological value. From an environmental point of view, these concretes do not emit pollutant leachate [26] and adopt the color of the aggregate used, thereby minimizing the visual impact caused [32].

\section{Conclusions}

The results obtained in the tests carried out led us to confirm the initial research hypothesis, and the following conclusions:

On the properties of fresh concrete:

- $\quad$ The addition of glass powder, as a substitute for cement with particles of dimension $\mathrm{d} 50=16 \mu \mathrm{m}$, to the manufacture of the concrete, whatever its dosage, did not cause any improvement in terms of workability. In fact, the higher the glass powder replacement percentage, the worse the workability of the concrete;

- The air content was higher with higher substitution of cement for glass powder. This fact increased the resistance of the concrete to the atmospheric phenomena of freeze-thaw cycles, without the need to include additives to achieve this effect;

- $\quad$ Replacing cement with glass powder caused a higher air content. For this reason, the density of the different concretes varied, decreasing when the substitution of cement for glass powder increased; and

- $\quad$ The consistency tests by means of a settlement test allowed us to classify these concretes within the group of fluid concretes, regardless of the dosage of glass powder used.

In terms of compressive strength:

- $\quad$ The use of glass in the binder increased the long-term compressive strengths of concrete;

- The long-term compressive strengths of concretes containing glass powder were higher than Bolomey's ones, whatever the amount of glass powder that the binder contained. Therefore, glass powder exerted an important activity in increasing the long-term compressive strength of concretes. At up to 50\% replacement of CEM I 52.5 $\mathrm{R}$ cement by glass powder, the compressive strength values obtained were important enough to classify these concretes in the group of building concretes. At above $50 \%$ substitution of CEM I 52.5 R cement by glass powder, the resistance values obtained allowed these concretes to be classified in the group of concretes for paving roads and highways;

- A mathematical model has been proposed to further analyze the experimental data. The model has proven to simulate quite well the results, as the errors were between $0.65 \%$ and $3.21 \%$ in relation to the calculated values of the final stable value of the compressive strength; and

- $\quad$ Due to all the characteristic described, this concrete is proposed as ideal as a surface protection layer against the action of corrosion in wind turbine foundations as well as the stabilization of the wind farm roads. The proposed use of this final waster as a binder in ecofriendly concrete has a global impact on circular economy and may reduce the emission of greenhouse gases, because the destiny of this waste would be landfill.

Author Contributions: Conceptualization, E.M.G.d.T. and M.I.M.-L.; methodology, D.A.-G., E.M.G.d.T., M.I.M.-L., S.G.-S. and S.P.; software, M.I.M.-L.; validation, S.G.-S., E.M.G.d.T. and M.I.M.L.; formal analysis, E.M.G.d.T., M.I.M.-L. and D.A.-G.; investigation, D.A.-G., E.M.G.d.T., M.I.M.-L., S.G.-S. and S.P.; data curation, E.M.G.d.T. and M.I.M.-L.; writing-original draft preparation, D.A.-G., E.M.G.d.T., S.G.-S., M.I.M.-L. and S.P.; writing-review and editing, E.M.G.d.T. and M.I.M.-L.; supervision, S.G.-S., M.I.M.-L. and S.P. All authors have read and agreed to the published version of the manuscript.

Funding: This research received no external funding. 
Institutional Review Board Statement: Not applicable.

Informed Consent Statement: Not applicable.

Data Availability Statement: Not applicable.

Conflicts of Interest: The authors declare no conflict of interest.

\section{References}

1. ONU Objetivos del Desarrollo Sostenible. Available online: https://www.un.org/sustainabledevelopment/es / (accessed on 18 October 2020).

2. ASCE. La Visión para la Ingeniería Civil en 2025; ASCE: Reston, VA, USA, 2006.

3. Rodríguez, F.; Fernández, G. Ingeniería sostenible: Nuevos objetivos en los proyectos de construcción. Rev. Ing. Constr. 2010, 25, 147-160. [CrossRef]

4. Fogarassy, C.; Finger, D. Theoretical and practical approaches of circular economy for business models and technological solutions. Resources 2020, 9, 76. [CrossRef]

5. Fundación Conama; Council Green Building; RCD Asociación. Economía circular en el ámbito de la construccion. In Proceedings of the Congreso Nacional del Medio Ambiente 2018, Madrid, Spain, 26-29 November 2018; pp. 1-63.

6. Švajlenka, J.; Kozlovská, M. Evaluation of the efficiency and sustainability of timber-based construction. J. Clean. Prod. 2020, 259. [CrossRef]

7. Vidrio España. Contribución Económica, Ambiental y Social del Sector del Vidrio en España (2014/1016); Vidrio España: Madrid, Spain, 2017; p. 44.

8. Marco, L.J.; García, E.; Más, M.I.; Alcaraz, V.; Luizaga, A. Estudio de la resistencia a compresión de morteros fabricados con conglomerante compuesto de polvo de vidrio. Inf. Constr. 2012, 64, 529-536. [CrossRef]

9. Hogland, W. Remediation of an old landsfill site: Soil analysis, leachate quality and gas production. Environ. Sci. Pollut. Res. Int. 1994, 9, 49-54. [CrossRef] [PubMed]

10. Slomski, V.G.; Lima, I.C.S.; Slomski, V.; Slavov, T. Pathways to urban sustainability: An investigation of the economic potential of untreated household solid waste (HSW) in the city of Saõ Paulo. Sustainability 2020, 12, 5249. [CrossRef]

11. Rashidian-Dezfouli, H.; Afshinnia, K.; Rangaraju, P.R. Efficiency of Ground Glass Fiber as a cementitious material, in mitigation of alkali-silica reaction of glass aggregates in mortars and concrete. J. Build. Eng. 2018, 15, 171-180. [CrossRef]

12. Serpa, D.; Santos Silva, A.; De Brito, J.; Pontes, J.; Soares, D. ASR of mortars containing glass. Constr. Build. Mater. 2013, 47, 489-495. [CrossRef]

13. Aliabdo, A.A.; Abd Elmoaty, A.E.M.; Aboshama, A.Y. Utilization of waste glass powder in the production of cement and concrete. Constr. Build. Mater. 2016, 124, 866-877. [CrossRef]

14. Thomas, C.; de Brito, J.; Corinaldesi, V. Special issue high-performance eco-efficient concrete. Appl. Sci. 2021, 11, 1163. [CrossRef]

15. De Castro, S.; De Brito, J. Evaluation of the durability of concrete made with crushed glass aggregates. J. Clean. Prod. 2013, 41, 7-14. [CrossRef]

16. Idir, R.; Cyr, M.; Tagnit-Hamou, A. Use of fine glass as ASR inhibitor in glass aggregate mortars. Constr. Build. Mater. 2010, 24, 1309-1312. [CrossRef]

17. García Del Toro, E.M.; Más López, M.I. Study of new formations of C-S-H in manufactured with glass powder as binder mortar. Ing. Investig. 2018, 38, 24-32. [CrossRef]

18. Liu, M. Incorporating ground glass in self-compacting concrete. Constr. Build. Mater. 2011, 25, 919-925. [CrossRef]

19. Parghi, A.; Shahria Alam, M. Physical and mechanical properties of cementitious composites containing recycled glass powder (RGP) and styrene butadiene rubber (SBR). Constr. Build. Mater. 2016, 104, 34-43. [CrossRef]

20. Nassar, R.U.D.; Soroushian, P. Strength and durability of recycled aggregate concrete containing milled glass as partial replacement for cement. Constr. Build. Mater. 2012, 29, 368-377. [CrossRef]

21. Schwarz, N.; Cam, H.; Neithalath, N. Influence of a fine glass powder on the durability characteristics of concrete and its comparison to fly ash. Cem. Concr. Compos. 2008, 30, 486-496. [CrossRef]

22. Shayan, A.; Xu, A. Performance of glass powder as a pozzolanic material in concrete: A field trial on concrete slabs. Cem. Concr. Res. 2007, 36, 457-468. [CrossRef]

23. Shao, Y.; Lefort, T.; Moras, S.; Rodriguez, D. Studies on concrete containing ground waste glass. Cem. Concr. Res. 2000, 30, 91-100. [CrossRef]

24. Guo, P.; Meng, W.; Nassif, H.; Gou, H.; Bao, Y. New perspectives on recycling waste glass in manufacturing concrete for sustainable civil infrastructure. Constr. Build. Mater. 2020, 257, 119579. [CrossRef]

25. Fernández Cánovas, M. Hormigon: Adaptado a la Instruccion para la Recepcion de Cementos y a la Instruccion de Hormigon Estructural Ehe, 10th ed.; CICCP: Girona, Spain; Garceta: Madrid, Spain, 2013.

26. Mas, M.I.; García, E.M.; Marco, L.J.; De Marco, J. Análisis de la Viabilidad Ambiental de la Utilización de Morteros Fabricados con Polvo de Vidrio en la Estabilización de Suelos. Inf. Tecnol. 2016, 27, 77-86. [CrossRef]

27. ANEFHOP UNE-EN 12350-5:2020. Ensayos de Hormigón Fresco. Parte 5: Ensayo de la Mesa de Sacudidas; UNE: Madrid, Spain, 2020; pp. 1-15. 
28. Comité Técnico CEN/TC 104 Hormigón y Productos Relacionados UNE-EN 12350-7: Ensayos de Hormigón Fresco. Parte 7: Contenido de aire Métodos de Presión; UNE: Madrid, Spain, 2020.

29. CTN 83-HORMIGÓN UNE-EN 1015-6:1999: Densidad Aparente del Hormigón Fresco 1999; UNE: Madrid, Spain, 1999.

30. AENOR UNE-EN 12350-2. Ensayos de Hormigón Fresco. Parte 2: Ensayo de Asentamiento; UNE: Madrid, Spain, 2006; pp. 1-9.

31. Hormigón, C. Técnico 83 UNE 83507 Rotura a Compresión; UNE: Madrid, Spain, 2004; p. 1.

32. Más-López, M.I.; del Toro, E.M.G.; Patiño, A.L.; García, L.J.M. Eco-friendly pavements manufactured with glass waste: Physical and mechanical characterization and its applicability in soil stabilization. Materials 2020, 13, 3727. [CrossRef]

33. Pereira-De-Oliveira, L.A.; Castro-Gomes, J.P.; Santos, P.M.S. The potential pozzolanic activity of glass and red-clay ceramic waste as cement mortars components. Constr. Build. Mater. 2012, 31, 197-203. [CrossRef]

34. Taha, B.; Nounu, G. Properties of concrete contains mixed colour waste recycled glass as sand and cement replacement. Constr. Build. Mater. 2008, 22, 713-720. [CrossRef]

35. Tan, K.H.; Du, H. Use of waste glass as sand in mortar: Part I-Fresh, mechanical and durability properties. Cem. Concr. Compos. 2013, 35, 109-117. [CrossRef]

36. Mirzahosseini, M.; Riding, K.A. Influence of different particle sizes on reactivity of finely ground glass as supplementary cementitious material (SCM). Cem. Concr. Compos. 2015, 56, 95-105. [CrossRef]

37. Fiol, F.; Thomas, C.; Muñoz, C.; Ortega-López, V.; Manso, J.M. The influence of recycled aggregates from precast elements on the mechanical properties of structural self-compacting concrete. Constr. Build. Mater. 2018, 182, 309-323. [CrossRef]

38. Lu, J.-X.; Duan, Z.-H.; Poon, C.S. Combined use of waste glass powder and cullet in architectural mortar. Cem. Concr. Compos. 2017, 82, 34-44. [CrossRef] 